\title{
Experimental Investigation of Flow Resistance in a Coal Mine Ventilation Air Methane Preheated Catalytic Oxidation Reactor
}

\author{
Bin Zheng, Yongqi Liu, Ruixiang Liu, Jian Meng, and Mingming Mao \\ School of Transportation and Vehicle Engineering, Shandong University of Technology, Zhangzhou Road 12, Zibo 255049, China \\ Correspondence should be addressed to Yongqi Liu; sdutliu@163.com
}

Received 26 September 2014; Revised 6 January 2015; Accepted 6 January 2015

Academic Editor: Agus Sasmito

Copyright (C) 2015 Bin Zheng et al. This is an open access article distributed under the Creative Commons Attribution License, which permits unrestricted use, distribution, and reproduction in any medium, provided the original work is properly cited.

\begin{abstract}
This paper reports the results of experimental investigation of flow resistance in a coal mine ventilation air methane preheated catalytic oxidation reactor. The experimental system was installed at the Energy Research Institute of Shandong University of Technology. The system has been used to investigate the effects of flow rate $\left(200 \mathrm{Nm}^{3} / \mathrm{h}\right.$ to $\left.1000 \mathrm{Nm}^{3} / \mathrm{h}\right)$ and catalytic oxidation bed average temperature $\left(20^{\circ} \mathrm{C}\right.$ to $\left.560^{\circ} \mathrm{C}\right)$ within the preheated catalytic oxidation reactor. The pressure drop and resistance proportion of catalytic oxidation bed, the heat exchanger preheating section, and the heat exchanger flue gas section were measured. In addition, based on a large number of experimental data, the empirical equations of flow resistance are obtained by the least square method. It can also be used in deriving much needed data for preheated catalytic oxidation designs when employed in industry.
\end{abstract}

\section{Introduction}

Coal mine methane emissions make up approximately $8 \%$ of the world's anthropogenic methane emissions, and the quantity of methane emissions from coal mining alone is over 25 million tons every year. Roughly $70 \%$ of the methane emissions come from coal mine ventilation air methane (VAM), which is not only a greenhouse gas but also a wasted energy resource if not utilized. As a greenhouse gas, $\mathrm{CH}_{4}$, which (17\%) is the second largest contributor to global warming after $\mathrm{CO}_{2}(55 \%)$, is over 21 times more effective in trapping heat in the atmosphere than carbon dioxide over a 100 -year period. As the air volume is large and the methane resource is diluted and varies in concentration and flow rate, ventilation air methane is the most difficult source of $\mathrm{CH}_{4}$ to be used as an energy source. Karakurt et al. [1] reported that methane concentration in coal mine ventilation air is low (0.1 1.5 vol.\%), and its effective utilization is considerably low. The combustion of lean methane-air mixtures combined with the recovery of the heat of reaction is an essential problem for the mining industry.

A number of studies have been conducted to determine the most efficient way to utilize this lean methane via combustion as well as to recover the energy thus produced. Due to the pretty low $\mathrm{CH}_{4}$ concentrations, the most promising solution seems to be autothermal combustion in reverseflow reactors. So far, most studies have focused on catalytic combustion in catalytic flow-reversal reactors (CFRRs) and thermal flow-reversal reactors (TFRRs). The earliest attempt at ventilation air methane (VAM) combustion in CFRR was supposedly carried out at the Boreskov Institute of Catalysis. At present, Salomons et al. [2] and Litto et al. [3] considered that CANMET in Canada is the most advanced in terms of the development of the technology of lean air methane mixtures combustion. Marín et al. [4] systematically compared the performance of particle beds and monolithic beds in catalytic reverse-flow reactors. Shi et al. [5] classified the existing technologies for coal mine methane mitigation and utilization. Tischer et al. [6] developed transient twoand three-dimensional simulations of catalytic combustion monoliths. Shahamiri and Wierzba [7] developed a onedimensional model to investigate the effects of operational conditions on CFRR. Shahamiri and Wierzba [8] studied the combustion of preheated lean mixtures of hydrogen with methane in a catalytic packed-bed reactor. Gosiewski et al. $[9,10]$ carried out a comparative assessment of TFRR and CFRR. It has been shown that both solutions have advantages and drawbacks. Li et al. [11, 12] built a flow-reversal strategy of CFRR based on the thermal front propagation velocity and a logic-based controller. Gosiewski et al. [13], Qi et al. 


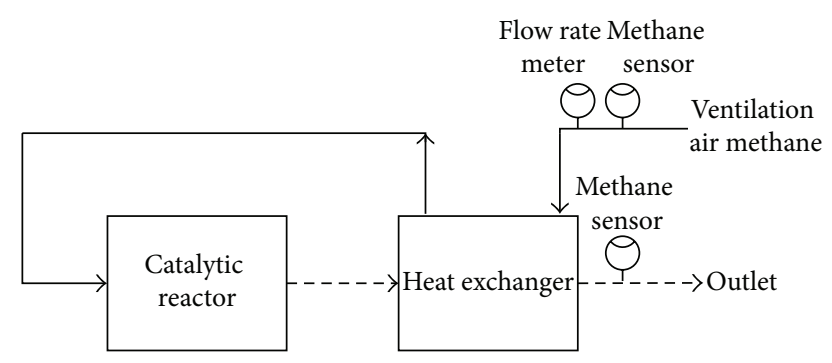

FIGURE 1: Preheated catalytic oxidation reactor operating principle and experimental schema.

[14], Gao et al. [15], and Zheng et al. [16] considered that TFRRs are regarded as an attractive alternative. Salvador et al. [17] reported that such reactors have long been employed, for example, for the homogeneous (thermal) combustion of volatile organic compounds (VOCs).

The common characteristic of CFRRs and TFRRs is reverse-flow in reactors. The drawbacks of their reactors are as follows. Firstly, the device occupies a large area because the reactor is packed with a large number of ceramic monolith blocks. Secondly, after a long time operation, a high maintenance cost is needed due to the damage of ceramic monolith blocks. Thirdly, the pressure drop is high and more energy is required to supply ventilation air methane. Finally, the control machine of the time-varying airflow direction is quite large and complex, and as a result, the control system is rather complex.

Zheng et al. [18] investigated a preheated catalytic oxidation reactor to combustion coal mine ventilation air methane. This reactor employs a new working principle and different CFRRs and TFRRs, which is not reverse-flow. The equipment used to recover exhaust flue gas heat is a wall-type heat exchanger. In this regard, Tahseen et al. [19], Golman and Julklang [20], Gao and Sun [21], and Zheng [22] studied waste heat recovery by a wall-type heat exchanger. The performance of the heat exchanger is reliable. The flow resistance of reactor is an important parameter. $\mathrm{Wu}$ and $\mathrm{Yu}$ [23] developed a fractal model for resistance of flow through porous media. Kushwaha et al. [24], Amelio and Morrone [25], and Liu et al. [26] studied the pressure drop of a flow-reversal reactor. The use of a preheated catalytic oxidation reactor for the flow resistance therefore requires detailed studies to determine the reasonable operating conditions. The objective of the present study is to investigate the effects of key operational parameters on flow resistance processes within the preheated catalytic reactor. It can also be used in deriving much needed data for preheated catalytic oxidation designs when employed in industry.

\section{Operating Principle}

A schematic diagram of the preheated catalytic reaction reactor being considered in the experiment is shown in Figure 1. VAM flows into the heat exchanger, where it is heated by the flue gas of high temperature from the catalytic reactor until it reaches the temperature of methane catalytic oxidation. Then preheated VAM flows of the heat exchanger

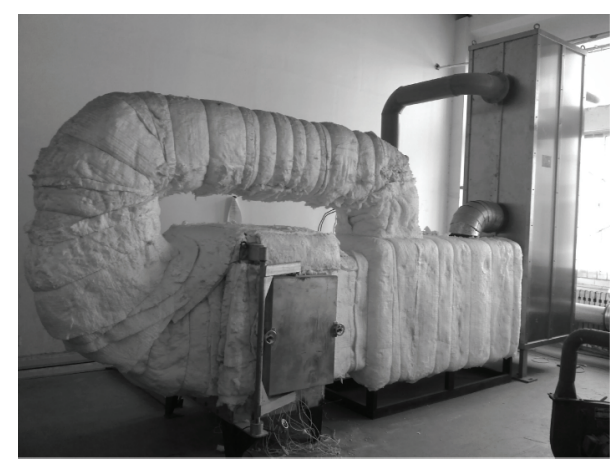

FIGURE 2: General view of the research and demonstration of preheated catalytic oxidation reactor apparatus.

and flows into the catalytic reactor, where VAM is catalytically combusted. The high temperature flue gas from the catalytic reactor flows into the heat exchanger to preheat VAM, and then the cooled flue gas is emitted into the atmosphere.

\section{Experimental Reactor System}

Tests were carried out in a preheated catalytic oxidation reactor built at the Energy Research Institute of Shandong University of Technology. A general view of the experimental apparatus is shown in Figure 2, while a simplified flowsheet of the apparatus is given in Figure 3.

The experimental system is divided into six parts: the gas supply system, the parameter acquisition system, the startup system, the differential pressure analysis system, the heat exchanger, and the catalytic oxidation bed. A schematic diagram of the experimental apparatus is shown in Figure 3. Mine ventilation air used in the experiment was a mixture air and natural gas, where the $\mathrm{CH}_{4}$ purity was $99.9 \%$. Compressed air from the air compressor through the gas regulating valve and pressure-relief valve mixes with the methane from methane cylinder in the mixer, and the mixture is then fed into the heat exchanger. The catalytic reactor consists of the startup system and the catalytic oxidation bed, which was surrounded with a layer of insulation ceramic fiber blanket which is $350 \mathrm{~mm}$ thick to prevent heat loss from the reactor to the surroundings. The startup system consists of some electrical heaters. To initiate the reaction, the catalytic oxidation bed was preheated from an ambient temperature to about $350^{\circ} \mathrm{C}$ by electrical heaters in the inlet position of the reactor. Once the bed was preheated, the electrical heater was extinguished and the lean methane mixture was supplied to the bed. The heating temperature and heating power in the startup process were controlled by the temperature control instrument. The catalytic oxidation bed, of which the length was $300 \mathrm{~mm}$ and the section was $600 \times$ $600 \mathrm{~mm}$ squared, was packed with catalytic ceramic monolith blocks (Figure 4) and a large number of straight and parallel channels. The block size was $100 \mathrm{~mm} * 100 \mathrm{~mm} * 100 \mathrm{~mm}$, and the density of the hole, which was square, was 300 meshes. The catalyst was Pd, which was loaded $0.28 \mathrm{wt} \%$. The type of support was $\gamma-\mathrm{Al}_{2} \mathrm{O}_{3}$. The heat exchanger was dividing wall-type, which consists of heat exchangers 1 and 2. Heat 


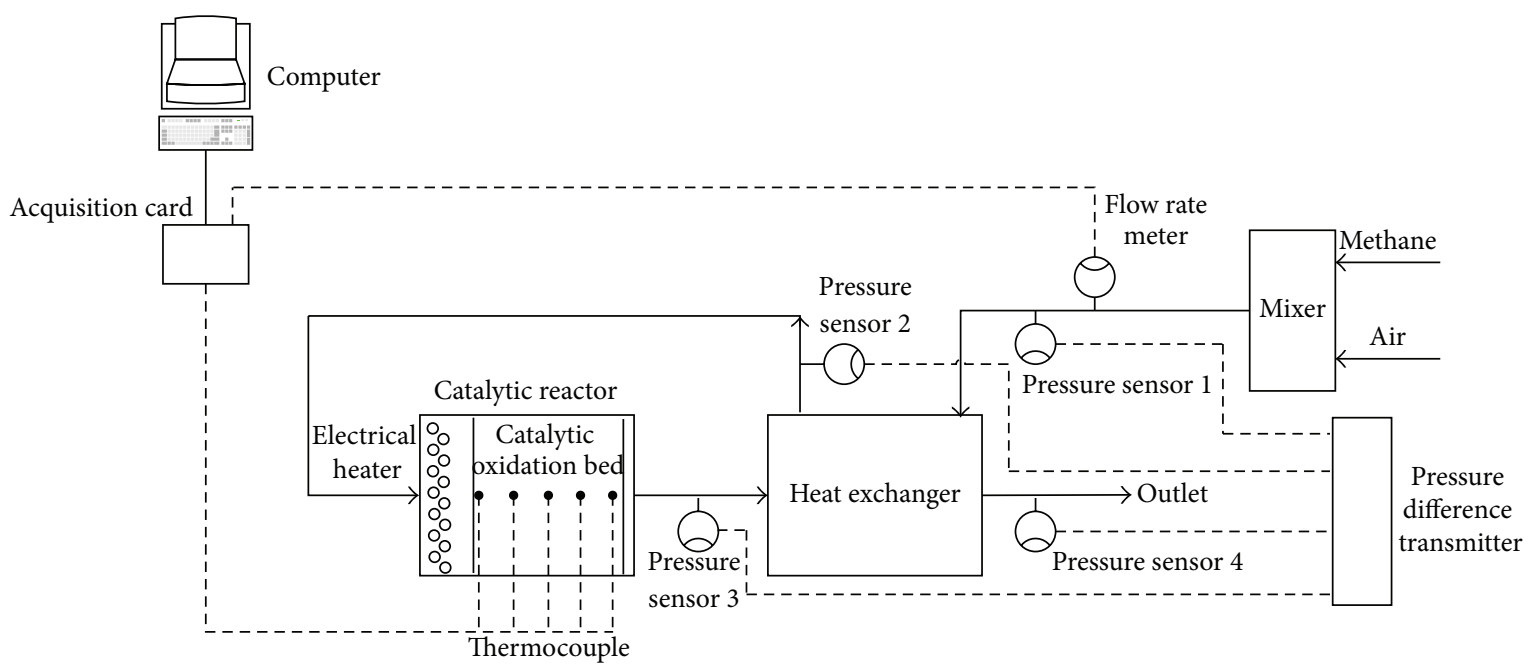

FIGURE 3: General overview of the research and demonstration of preheated catalytic oxidation reactor apparatus.

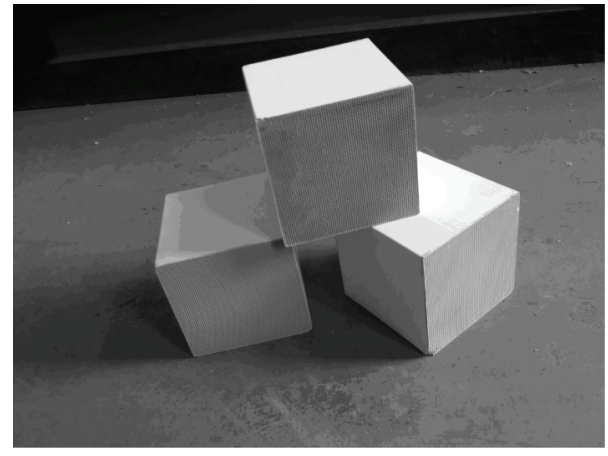

FIGURE 4: Catalytic ceramic monolith blocks.

exchanger 1 was $700 \mathrm{~mm}$ wide, $1100 \mathrm{~mm}$ high, and $2000 \mathrm{~mm}$ long. Heat exchanger 2 was $700 \mathrm{~mm}$ wide, $3000 \mathrm{~mm}$ high, and $700 \mathrm{~mm}$ long. There were 5 thermocouple measuring points arranged along the axis of the catalytic oxidation bed, and the output signal of the thermocouple connected to the computer can monitor the transient temperature field in the bed. Meanwhile, the signal of VAM flow rate was also connected to the computer. There were 4 pressure sensors installed in the intake and exhaust of the heat exchanger and the catalytic reactor; the output signal of pressure connected to pressure difference transmitter can monitor the pressure drop field in the catalytic reactor and the heat exchanger. The pressure sensor was stagnation pressure tube, whose type was TPS-08-500-T. The experimental uncertainty for the pressure drop was $\pm 1 \%$.

After the experimental system is well connected and the experimental instrument, equipment, and airtightness are checked, the experiment is started. The experimental procedures are as follows.

(1) Turn on the power switch of the device; the system is then connected to the electricity supply and the air compressor is turned on.
(2) Turn on the computer that is connected with the data acquisition card; open the data acquisition operating system on the computer; set the required acquisition channels and parameters, and the values of each parameter are displayed online.

(3) Open the methane cylinder and adjust the pressurerelief valve.

(4) Open both the valves for air and methane and set the startup flow rate values.

(5) Turn on the startup system. When the catalytic oxidation bed is preheated to about $350^{\circ} \mathrm{C}$, turn off the startup system and set the desired flow rate values and the experimental system starts up successfully.

(6) Adjust the operating parameters according to the experimental conditions, and collect and record the data. Repeat the above process for the next set of conditions.

(7) When the experiment is finished, first turn off the methane gas. Then turn off the methane pressurerelief valve, stop data acquisition, and store the experimental data and then shut down the computer.

(8) Close the flowmeter and then turn off the air source. Turn off the power control supply.

(9) For the next experiment, repeat the above operations.

To investigate the flow resistance performance of the reactor, some pressure drop parameters were used. $\Delta P$ was the loss of total pressure in the reactor, which was the difference between pressure sensor 1 and pressure sensor $4 . \Delta P_{1}$ was the pressure drop of VAM preheating section in the heat exchanger, which was the difference between pressure sensor 1 and pressure sensor 2. $\Delta P_{2}$ was the pressure drop of catalytic oxidation bed (the pipe resistance is ignored), which was the difference between pressure sensor 2 and pressure sensor 3 . $\Delta P_{3}$ was the pressure drop of flue gas section in the heat exchanger, which was the difference between pressure sensor 3 and pressure sensor 4 . 


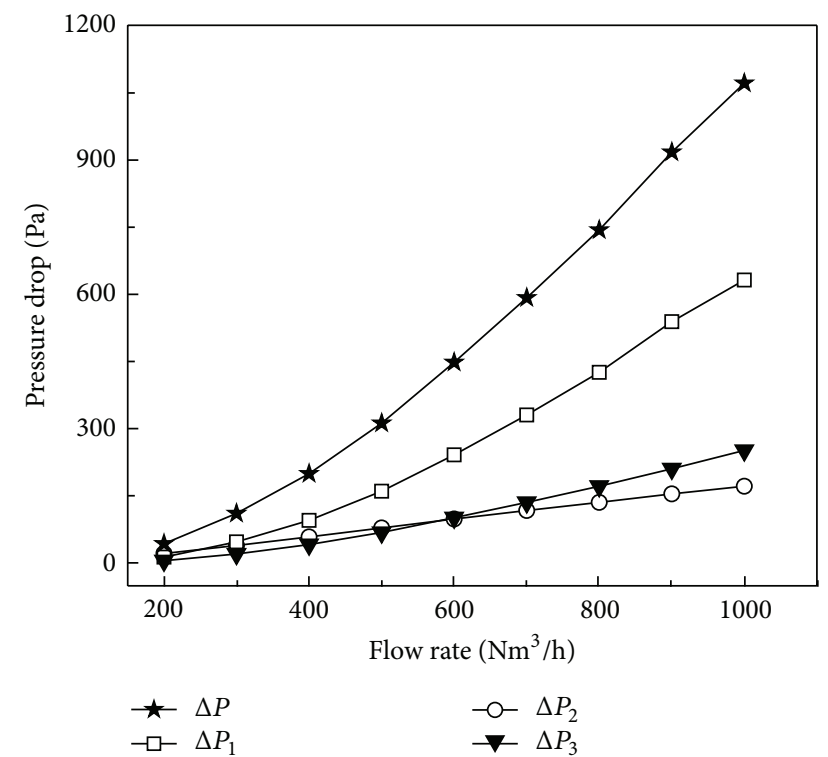

FIGURE 5: Pressure drop distribution in preheated catalytic oxidation reactor with different flow rates.

\section{Results and Discussions}

4.1. Effect of Flow Rate. Figure 5 shows the pressure drop results of flow rate from $200 \mathrm{Nm}^{3} / \mathrm{h}$ to $1000 \mathrm{Nm}^{3} / \mathrm{h}$ in normal condition. As can be seen from Figure 5, with the increase of flow rate, the pressure drop of different sections all increases, but the trends of development are different. The pressure drops of the preheating section and the flue gas section in the heat exchanger increase quadratically, but the pressure drop of the catalytic oxidation bed increases linearly. The reason for this is that the heat exchanger is dividing walltype with a large number of fins arranged in the internal heat exchanger in order to enhance the heat transfer effect, so the heat exchanger can be seen as a porous medium. According to Darcy's law, the pressure drops of the preheating section and the flue gas section increase quadratically because the Reynolds number in the heat exchanger is between 17773 and 88640, which is far higher than the critical Reynolds number (2320), but the pressure drop of catalytic oxidation bed increases linearly because the Reynolds number in the catalytic oxidation bed is between 398 and 1987, which is under critical Reynolds number (2320). Figure 6 shows the resistance proportion results of flow rate from $200 \mathrm{Nm}^{3} / \mathrm{h}$ to $1000 \mathrm{Nm}^{3} / \mathrm{h}$ in cold test condition. Figure 6 shows that if the other conditions remain the same, when the flow rate ranges from $200 \mathrm{Nm}^{3} / \mathrm{h}$ to $1000 \mathrm{Nm}^{3} / \mathrm{h}$, that is, as the flow rate increases, the resistance proportion of the preheating section and the flue gas section increases, but the resistance proportion of catalytic oxidation bed decreases. The pressure drop of the heat exchanger becomes a chief component in the preheated catalytic oxidation reactor.

4.2. Effect of Average Temperature in Catalytic Oxidation Bed. Figure 7 shows the pressure drop results of catalytic oxidation bed average temperature from $20^{\circ} \mathrm{C}$ to $560^{\circ} \mathrm{C}$ and a flow rate of $500 \mathrm{Nm}^{3} / \mathrm{h}$. Figure 7 shows that if the other conditions

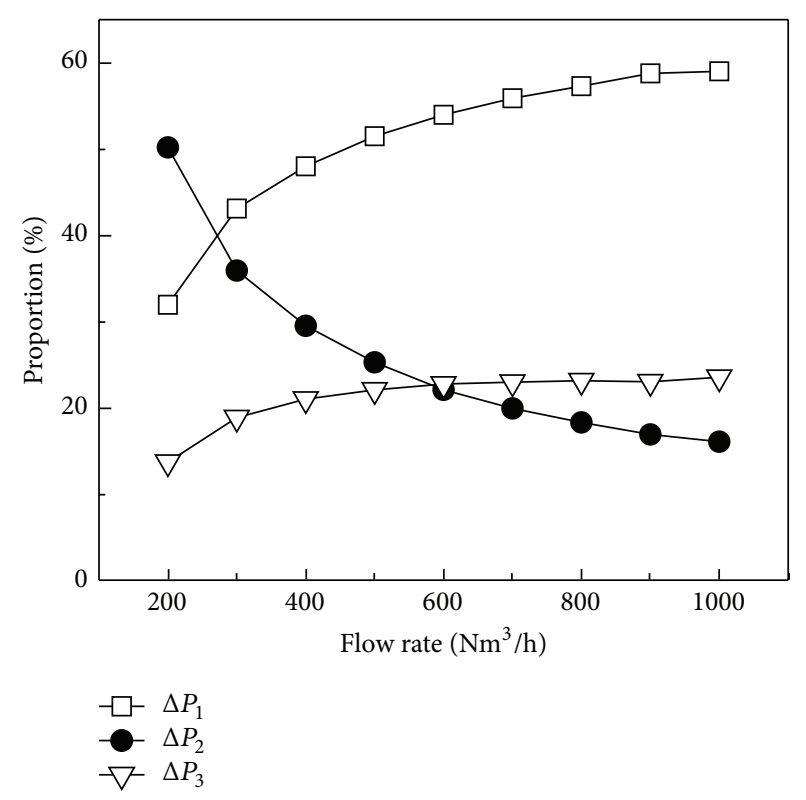

FIGURE 6: Resistance proportion distribution with different flow rates.

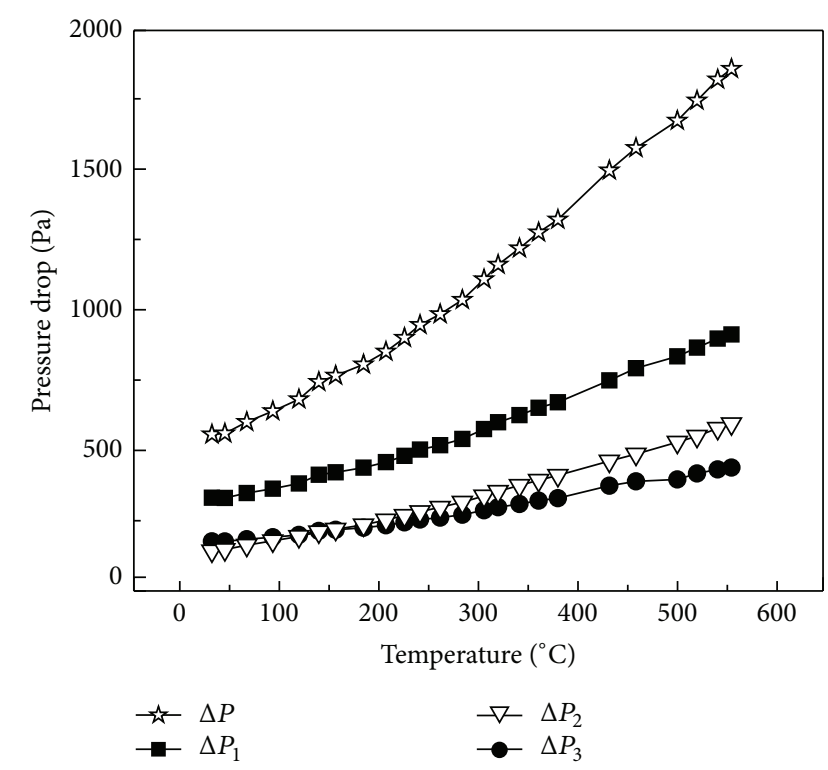

FIGURE 7: Pressure drop distribution with different catalytic oxidation bed average temperatures.

remain the same, as the average temperature increases, the pressure drop of different sections all increases, but the trends of development are different. The pressure drops of the preheating section and the flue gas section in the heat exchanger increase exponentially, but the pressure drop of the catalytic oxidation bed increases linearly. The reason for this is that the higher the catalytic oxidation bed average temperature is, the higher the VAM velocity and viscosity are and the higher the pressure drop is. Figure 8 shows the resistance proportion results of the catalytic oxidation bed average temperature from $20^{\circ} \mathrm{C}$ to $560^{\circ} \mathrm{C}$ and a flow rate of $500 \mathrm{Nm}^{3} / \mathrm{h}$. As can be seen from Figure 8, with the increase 

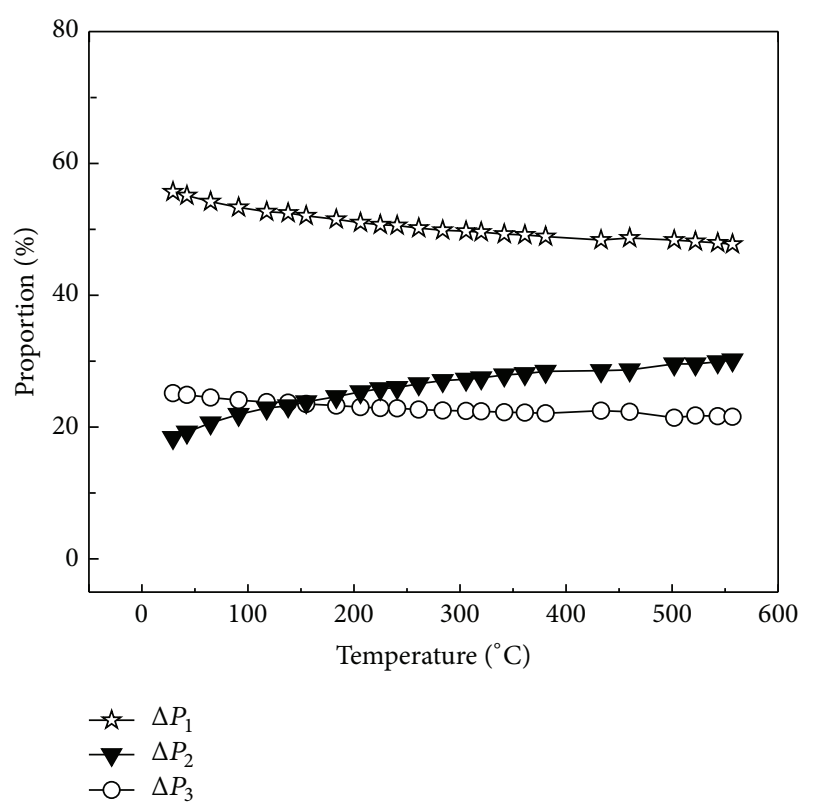

FIGURE 8: Resistance proportion distribution with different catalytic oxidation bed average temperatures.

of the bed average temperature, the resistance proportion of the catalytic oxidation bed increases, while the resistance proportion of the preheating section and the flue gas section decreases.

\subsection{Empirical Equation of Flow Resistance in Preheated} Catalytic Oxidation Reactor. The widely employed resistance model for flow through porous media was proposed by Ergun [27] in 1952. This model is called Ergun equation. Based on a large number of experimental data and Ergun equation, the empirical equations of flow resistance are obtained by the least square method. Equation (1) is the empirical equation of the preheating section in the heat exchanger, and Figure 9 shows the contrast of the experimental results and the calculated results. As can be seen from Figure 9, the goodness of fit is high, the correlation coefficient is 0.991 , and the maximum relative error is less than $\pm 4.7 \%$. The following equation is quite suitable in the $T_{1}$ region of $293 \mathrm{~K}$ to $503 \mathrm{~K}$ and in the $v_{1}$ region of $3.7 \mathrm{~m} / \mathrm{s}$ to $6.2 \mathrm{~m} / \mathrm{s}$ :

$$
\Delta P_{1}=43.07\left(\frac{T_{1}}{293}\right)^{1.5} \times \frac{403.4}{T_{1}+110.4} \times \frac{2 \rho_{0}^{2} v_{1}^{2} T_{1}}{1.293 \times 273},
$$

where $T_{1}$ is the average temperature of intake and exhaust in the preheating section, $\mathrm{K} ; \rho_{0}$ is the VAM density in normal condition, $\mathrm{kg} / \mathrm{m}^{3} ; v_{1}$ is the VAM flow velocity in the preheating section in normal condition, $\mathrm{m} / \mathrm{s}$.

Equation (2) is the empirical equation of the flue gas section in the heat exchanger, and Figure 10 shows the contrast of the experimental results and the calculated results. Figure 9 shows that the goodness of fit is high, the correlation coefficient is 0.996 , and the maximum relative error is less than $\pm 6.5 \%$. Equation (1) is quite suitable in the $T_{3}$ region

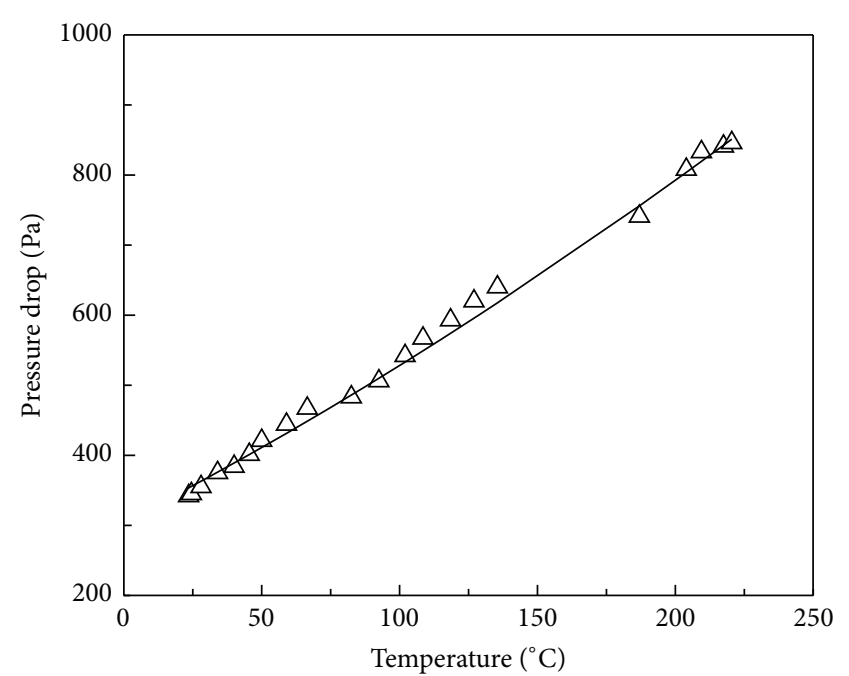

$\triangle$ Experimental results

- Calculated results

FIGURE 9: Contrast of the experimental results and the calculated results in the heat exchanger preheating section.

from $293 \mathrm{~K}$ to $553 \mathrm{~K}$ and in the $v_{3}$ region from $3.7 \mathrm{~m} / \mathrm{s}$ to $6.2 \mathrm{~m} / \mathrm{s}$ :

$$
\Delta P_{3}=16.99 \times\left(\frac{T_{2}}{293}\right)^{1.5} \times \frac{403.4}{T_{3}+110.4} \times \frac{2 \rho_{0}^{2} v_{3}^{2} T_{3}}{1.293 \times 273}
$$

where $T_{3}$ is the average temperature of intake and exhaust in the flue gas section, $\mathrm{K} ; \rho_{0}$ is the VAM density in normal condition, $\mathrm{kg} / \mathrm{m}^{3} ; v_{3}$ is the VAM flow velocity in the flue gas section in normal condition, $\mathrm{m} / \mathrm{s}$.

Equation (3) is the empirical equation of the catalytic oxidation bed, and Figure 11 shows the contrast of the experimental results and the calculated results. Figure 11 shows that the goodness of fit is high and the maximum relative error is less than $\pm 4.6 \%$. The following equation is quite suitable in the $T_{2}$ region from $293 \mathrm{~K}$ to $833 \mathrm{~K}$ and in the $v_{3}$ region of $0.15 \mathrm{~m} / \mathrm{s}$ to $1.74 \mathrm{~m} / \mathrm{s}$ :

$$
\begin{aligned}
\Delta P_{2}= & {\left[56.75 \frac{(1-\varepsilon)^{2} \mu}{\varepsilon^{3} d_{p}^{2}} v+0.0067 \frac{1-\varepsilon}{\varepsilon^{3} d_{p}} \rho_{0} v^{2}\right] } \\
& \cdot\left(\frac{T_{2}}{293}\right)^{0.18} \cdot L,
\end{aligned}
$$

where $\varepsilon$ is the void ratio of catalytic ceramic monolith block; $\mu$ is the coefficient of kinetic viscosity, $\mathrm{kg} /(\mathrm{m} \cdot \mathrm{s}) ; d_{p}$ is the equivalent diameter of hole in catalytic ceramic monolith block, $\mathrm{m} ; v$ is the VAM velocity in the catalytic oxidation bed intake, $\mathrm{m} / \mathrm{s} ; T_{2}$ is the average temperature of the catalytic oxidation bed, $\mathrm{K} ; L$ is the axial length of the catalytic oxidation bed, $\mathrm{m} ; \rho_{0}$ is the VAM density in normal condition, $\mathrm{kg} / \mathrm{m}^{3}$. 


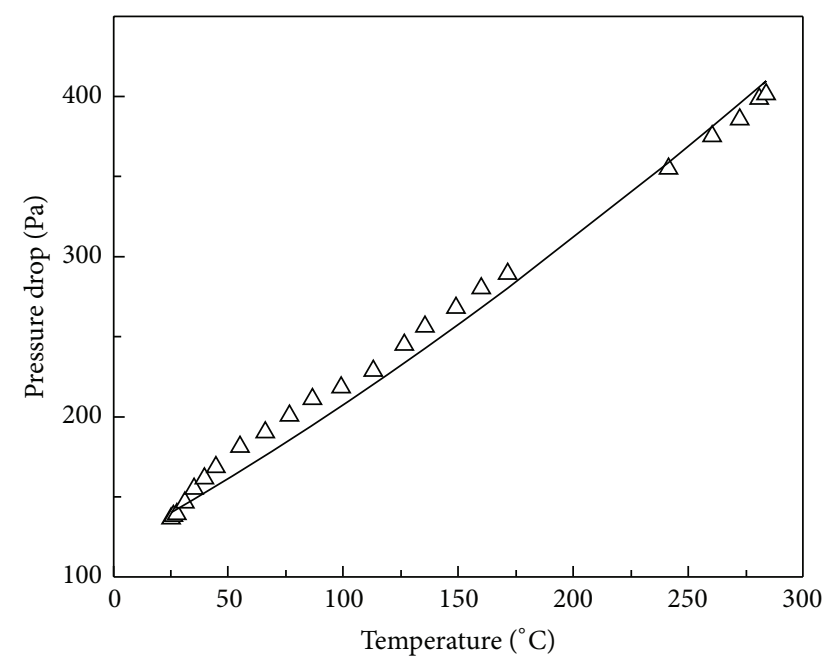

$\triangle$ Experimental results

— Calculated results

FIGURE 10: Contrast of the experimental results and the calculated results in the heat exchanger flue gas section.

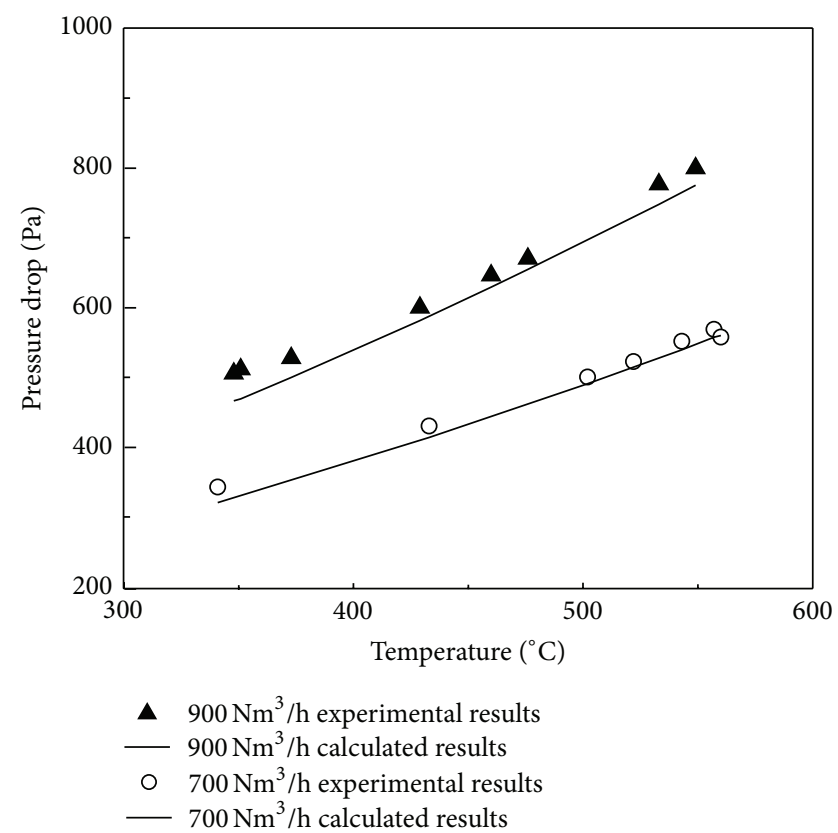

FIgURE 11: Contrast of the experimental results and the calculated results in the catalytic oxidation bed.

\section{Conclusions}

The main conclusions of the present study are as follows.

(1) With the increase of flow rate, the pressure drop of different sections all increases, but the trends of development are different. The pressure drops of the preheating section and the flue gas section in the heat exchanger increase quadratically, but the pressure drop of catalytic oxidation bed increases linearly. As the flow rate increases, the resistance proportion of the preheating section and the flue gas section increases, but the resistance proportion of the catalytic oxidation bed decreases. The pressure drop of the heat exchanger becomes a chief component in the preheated catalytic oxidation reactor.

(2) If the other conditions remain the same, as the average temperature increases, the pressure drop of different sections all increases, but the trends of development are different. The pressure drops of the preheating section and the flue gas section in the heat exchanger increase exponentially, but the pressure drop of the catalytic oxidation bed increases linearly. With the increase of the bed average temperature, the resistance proportion of the catalytic oxidation bed increases, but the resistance proportion of the preheating section and the flue gas section decreases.

(3) Based on a large number of experimental data, the empirical equations of flow resistance are obtained by the least square method; the goodness of fit is high. It can also be used in deriving much needed data for preheated catalytic oxidation designs when employed in industry.

\section{Conflict of Interests}

The authors declare that there is no conflict of interests regarding the publication of this paper.

\section{Acknowledgments}

This work was supported by the China National 863 High Technology Fund Project (2009AA063202), Shandong Provincial Science and Technology Development Program, China (2012GGX10417), and Shandong Provincial Natural Science Foundation, China (ZR2013EEQ005 and ZR2013EEQ008).

\section{References}

[1] I. Karakurt, G. Aydin, and K. Aydiner, "Mine ventilation air methane as a sustainable energy source," Renewable and Sustainable Energy Reviews, vol. 15, no. 2, pp. 1042-1049, 2011.

[2] S. Salomons, R. E. Hayes, M. Poirier, and H. Sapoundjiev, "Flow reversal reactor for the catalytic combustion of lean methane mixtures," Catalysis Today, vol. 83, no. 1-4, pp. 59-69, 2003.

[3] R. Litto, R. E. Hayes, H. Sapoundjiev et al., "Optimization of a flow reversal reactor for the catalytic combustion of lean methane mixtures," Catalysis Today, vol. 117, no. 4, pp. 536-542, 2006.

[4] P. Marín, M. A. G. Hevia, S. Ordóñez, and F. V. Díez, "Combustion of methane lean mixtures in reverse flow reactors: comparison between packed and structured catalyst beds," Catalysis Today, vol. 105, no. 3-4, pp. 701-708, 2005.

[5] S. Shi, B. Andrew, G. Hua, and M. Cliff, "An assessment of mine methane mitigation and utilization technologies," Progress in Energy and Combustion Science, vol. 31, no. 2, pp. 123-170, 2005.

[6] S. Tischer, C. Correa, and O. Deutschmann, "Transient threedimensional simulations of a catalytic combustion monolith 
using detailed models for heterogeneous and homogeneous reactions and transport phenomena," Catalysis Today, vol. 69, no. 1-4, pp. 57-62, 2001.

[7] S. A. Shahamiri and I. Wierzba, "Modeling catalytic oxidation of lean mixtures of methane-air in a packed-bed reactor," Chemical Engineering Journal, vol. 149, no. 1-3, pp. 102-109, 2009.

[8] S. A. Shahamiri and I. Wierzba, "Simulation of catalytic oxidation of lean hydrogen-methane mixtures," International Journal of Hydrogen Energy, vol. 34, no. 14, pp. 5785-5794, 2009.

[9] K. Gosiewski, Y. S. Matros, K. Warmuzinski, M. Jaschik, and M. Tanczyk, "Homogeneous vs. catalytic combustion of lean methane-air mixtures in reverse-flow reactors," Chemical Engineering Science, vol. 63, no. 20, pp. 5010-5019, 2008.

[10] K. Gosiewski and A. Pawlaczyk, "Catalytic or thermal reversed flow combustion of coal mine ventilation air methane: what is better choice and when?" Chemical Engineering Journal, vol. 238, pp. 78-85, 2014.

[11] Z. Li, Z. Qin, Y. Zhang et al., "A control strategy of flow reversal with hot gas withdrawal for heat recovery and its application in mitigation and utilization of ventilation air methane in a reverse flow reactor," Chemical Engineering Journal, vol. 228, no. 15, pp. 243-255, 2013.

[12] Z. Li, Z. Qin, Z. Wu et al., "Fuzzy logic control of a reverse flow reactor for catalytic oxidation of ventilation air methane," Control Engineering Practice, vol. 25, no. 1, pp. 112-122, 2014.

[13] K. Gosiewski, A. Pawlaczyk, and M. Jaschik, “Thermal combustion of lean methane-air mixtures: flow reversal research and demonstration reactor model and its validation," Chemical Engineering Journal, vol. 207-208, pp. 76-84, 2012.

[14] X. Qi, Y. Liu, H. Xu, Z. Liu, and R. Liu, "Modeling thermal oxidation of coal mine methane in a non-catalytic reverse-flow reactor," Strojniški vestnik-Journal of Mechanical Engineering, vol. 60, no. 7-8, pp. 495-505, 2014.

[15] Z. Gao, Y. Liu, and Z. Gao, "Heat extraction characteristic of embedded heat exchanger in honeycomb ceramic packed bed," International Communications in Heat and Mass Transfer, vol. 39, no. 10, pp. 1526-1534, 2012.

[16] B. Zheng, Y.-Q. Liu, R.-X. Liu, Z.-Q. Gao, and J. Meng, "Oxidation of coal mine ventilation air methane in thermal reverse-flow reactor," Journal of the China Coal Society, vol. 34, no. 11, pp. 1475-1478, 2009.

[17] S. Salvador, J. M. Commandré, and Y. Kara, "Thermal recuperative incineration of VOCs: CFD modelling and experimental validation," Applied Thermal Engineering, vol. 26, no. 17-18, pp. 2355-2366, 2006.

[18] B. Zheng, Y. Liu, R. Liu, S. Chen, M. Mao, and J. Meng, "Starting characteristics of ventilation air methane preheating catalytic oxidation reactor," Journal of China Coal Society, vol. 39, no. 6, pp. 1084-1088, 2014.

[19] T. A. Tahseen, M. Ishak, and M. M. Rahman, "An overview on thermal and fluid flow characteristics in a plain plate finned and un-finned tube banks heat exchanger," Renewable and Sustainable Energy Reviews, vol. 43, pp. 363-380, 2015.

[20] B. Golman and W. Julklang, "Simulation of exhaust gas heat recovery from a spray dryer," Applied Thermal Engineering, vol. 73, no. 15, pp. 899-913, 2014.

[21] W. Gao and J. Sun, "Heat transfer characteristics of flowing granular waved moving bed under vibration condition," China Powder Science and Technology, vol. 9, no. 3, pp. 1-4, 2003.

[22] B. Zheng, Y. Liu, R. Liu, Z. Wang, R. Yu, and X. Qi, "Experimental investigation of heat transfer characteristics of calcined petroleum coke fin-and-tube waste heat exchanger," The Open Fuels \& Energy Science Journal, vol. 7, no. 1, pp. 20-25, 2014.

[23] J. Wu and B. Yu, "A fractal resistance model for flow through porous media," International Journal of Heat and Mass Transfer, vol. 50, no. 19-20, pp. 3925-3932, 2007.

[24] A. Kushwaha, M. Poirier, H. Sapoundjiev, and R. E. Hayes, "Effect of reactor internal properties on the performance of a flow reversal catalytic reactor for methane combustion," Chemical Engineering Science, vol. 59, no. 19, pp. 4081-4093, 2004.

[25] M. Amelio and P. Morrone, "Numerical evaluation of the energetic performances of structured and random packed beds in regenerative thermal oxidizers," Applied Thermal Engineering, vol. 27, no. 4, pp. 762-770, 2007.

[26] Y.-Q. Liu, Z.-X. Zhang, Z.-Q. Gao, R.-X. Liu, and B. Zheng, "Numerical simulation on resistance of the regenerative oxidation bed for ventilation air methane," Journal of the China Coal Society, vol. 35, no. 6, pp. 946-950, 2010.

[27] S. Ergun, "Fluid flow through packed columns," Chemical Engineering Progress, vol. 48, pp. 89-94, 1952. 

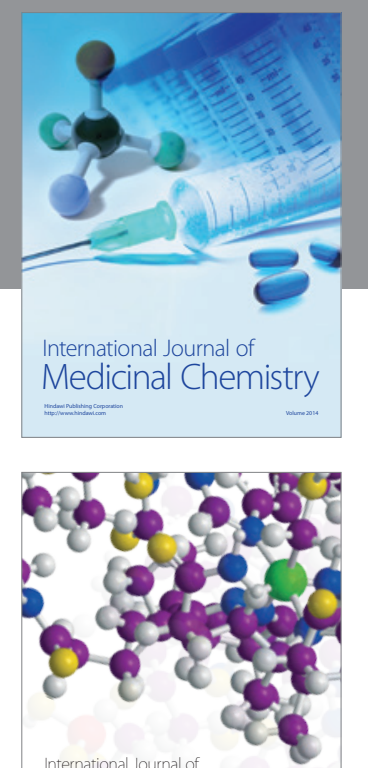

\section{Carbohydrate} Chemistry

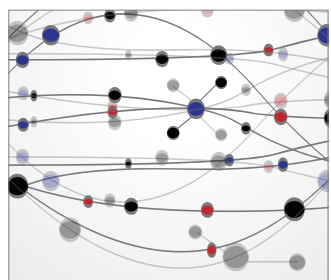

The Scientific World Journal
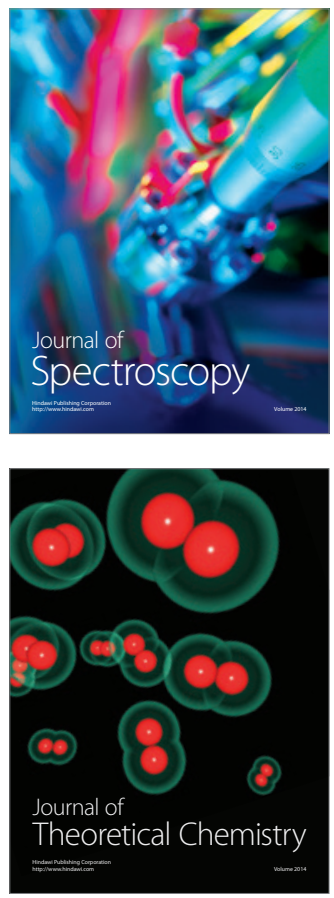
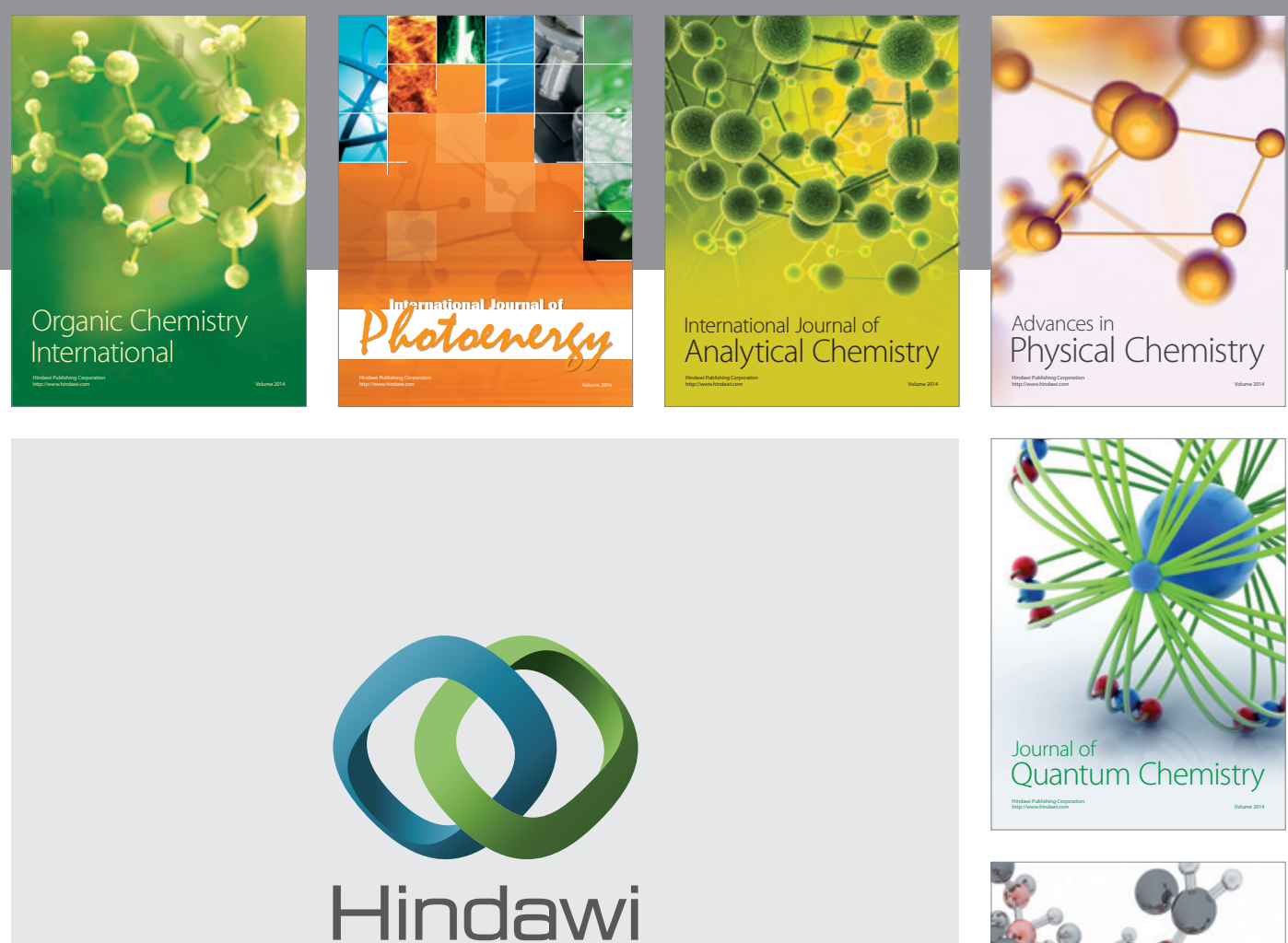

Submit your manuscripts at

http://www.hindawi.com

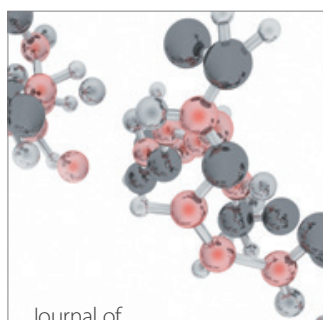

Analytical Methods

in Chemistry

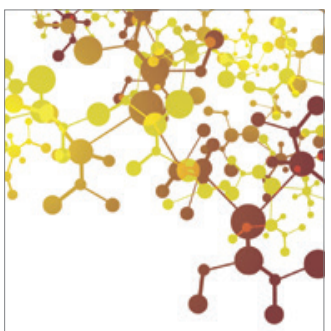

Journal of

Applied Chemistry

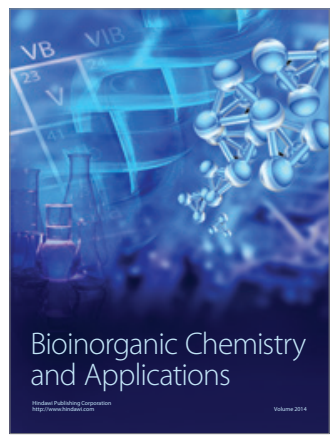

Inorganic Chemistry
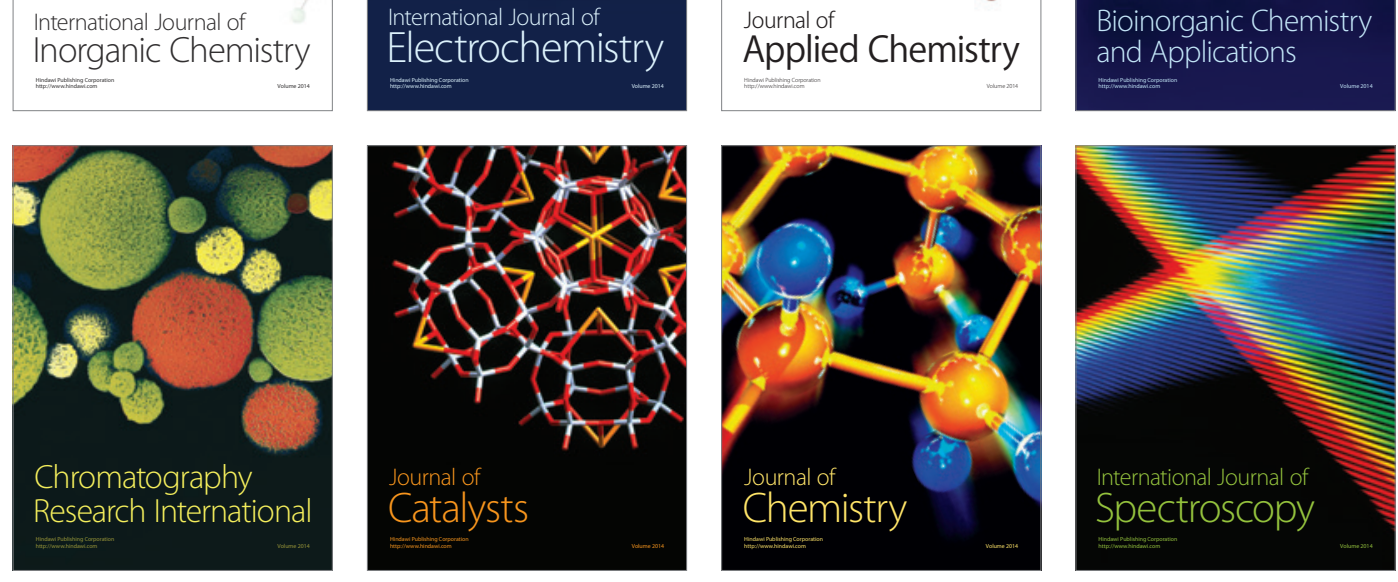